\title{
MPRA
}

Munich Personal RePEc Archive

\section{Dynamics of social trust and human capital in the learning process: The case of the Japan garment cluster in the period 1968-2005}

yamamura, eiji

17 May 2008

Online at https://mpra.ub.uni-muenchen.de/10251/

MPRA Paper No. 10251, posted 01 Sep 2008 05:48 UTC 


\title{
Dynamics of social trust and human capital in the learning process: The case of the Japan garment cluster in the period 1968-2005
}

\author{
Eiji Yamamura,* \\ Department of Economics, Seinan Gakuin University, 6-2-92 Nishijin Sawaraku \\ Fukuoka 814-8511, Japan
}

\begin{abstract}
This paper examined how and the extent to which human capital and social trust are associated with the learning process of a manager in making operations decisions through experience. To this end, using a data set originally and purposively constructed by the author, I investigate the development and transformation of the garment industry cluster region of Kojima, Japan. The major findings through statistical estimations are as follows. (1) In the cluster development stage, the social trust of an enterprise and its manager's experiences in firm operations could be regarded as forming a complimentary association. (2) In the stage following cluster development, however, a manager's human capital as accumulated through schooling and personal experience becomes complimentary instead of social trust.
\end{abstract}

JEL Classification: L2, O1.

Keywords: Social trust, Human capital, Bayesian learning

\footnotetext{
${ }^{*}$ Tel: 81-92-823-4543, Fax: 81-92-823-2506

E-mail address:cyl02111@nifty.com
} 


\section{Introduction}

It is widely and generally acknowledged that the improvement of individual faculties through past experiences plays a critical role in economic development (Shultz, 1975). Existing literature applies the Bayesian learning process, in which previous decisions and outcomes provide new information and thereby improve decisions, to theoretically clarify the accumulation of human capital (Jovanovic and Nyarko 1996). There has recently been growing interest in such leaning mechanisms from the empirical point of view, and hence a growing number of studies have attempted to explore the developmental process based upon this learning model (Munshi 2004; Foster and Rosenzweig 1995; Goux and Maurin 2007; Yamauchi 2004 )1. On the other hand, school education, which generates human capital, has also convincingly been argued as an important factor of economic development (Yamamura et al. 2003). Although, roughly speaking, both leaning and schooling can be thought of as making great contributions to the accumulation of human capital, their features and functions cannot be considered the same indiscriminately. Accordingly, the effects of human capital on economic development should be divided twofold.

A number of crucial notions concerning interpersonal relations, such as social trust, social norms, and reputation, have been increasingly explored in the fields of economics and sociology (e.g., Alesina and La Ferrara 2002; Coleman 1990; Fukuyama 1995; Granovetter 1985; Kandori, 1992; Sugden 1989; Putnam 1993, 2000; Vega-Redondo 2006; Yamagishi et al. 1998). These notions are formed as a consequence of long term and intense personal interaction, especially within a community formed as a long-established and closely knitted group. For instance, under conditions such as communities in developing countries where the market is still far from perfect and therefore does not sufficiently function, and where formal legal institutions have not yet been established, social trust among community members plays a relatively important role in mitigating problems caused by market imperfection and the scarcity of formal institutions (Hayami 1995). In order to assess the role of mutual trust, merchant trade has been explored using available historical evidence from the medieval era (Greif, 1994), and empirical case studies have been conducted in modern developing countries (Banarjee and Duflo 2000; Banarjee and Munshi 2004; McMillan and Woodruff 1999). Previous literature also provides evidence, using cross-country data, that social trust and social capital play a significant role in realizing high economic performance (e.g.,

\footnotetext{
${ }^{1}$ In particular, technology diffusion is examined within the learning mechanism framework.
} 
Hall and Jones 1999; Knack 2003; Knack and Keefer 1997; Zak and Knack 2001)2. However, it has also been observed that social capital failed to cause economic development (Miguel et al. 2005). These ostensibly conflicting findings imply that the role of social trust in economic development, may change over time. This is the focus of the current study.

Learning processes, social trust and schooling are considered to not only make a great contribution to economic development independently but also interact with each other to become the engine of development. To take an example, the complementary relationship between schooling and learning processes has been empirically explored (Rosenzweig 1995; Yamauchi 2004). These studies analyzed how schooling enhances the effects of learning, thereby improving the precision of decision making. Such research, however, puts focus upon only one phase of the developmental process and therefore does not examine how the association between schooling and learning processes changes over time from the viewpoint of long-term processes. For this purpose, an empirical approach using data covering a long period of time is necessary. On the other hand, although it is also necessary to investigate the association between socio-economic factors such as social trust and learning processes, few studies have been conducted to date ${ }^{3}$. Accordingly, I am concerned in this paper with the question of how the associations between schooling, social trust and leaning processes evolve and how their interactions influence economic development. To accomplish this, I examine the long term development process of the Kojima region, the largest garment industry cluster in Japan.

Although at one time the Kojima region had scarce arable land was a relatively less developed area, rapid economic growth occurred due to the emergence of garment clusters in the post-war period. More recently, however, the amount of output within the Kojima region has decreased because of the relocation of production to regions outside Kojima. The Kojima region experienced considerable change in the post-war period. For these reasons, the Kojima region is an appropriate target for investigating the different phases of the development process. Although I make use of available published production data at the enterprise level for selected years covering a span of about 40 years, there are limitations preventing a sufficiently thorough investigation of the development process in detail. To compensate for this, I also conducted a number

2 Hall and Jones (1999) constructed an index of 'social infrastructure' instead of the generalized concepts of trust or social capital.

3 Foster and Resenzweig (1995) indicated that information spillover is promoted by learning effects through interaction among neighbors, leading to a rise in agricultural productivity. 
of reconnaissance and field research trips to Kojima to collect original survey data from existing enterprises. Such data comprised of published and original survey data allows me to provide an empirical assessment of the effects schooling and social trust have on the learning process.

The organization of this paper is as follows: Section 2 provides a simple economic model on which the empirical analysis is based, and then postulates a testable hypothesis. A brief description of the data collection is presented and the developmental process of the Kojima region during the past 40 years is overviewed in Section 3. Section 4 presents a regression model and discusses the results of the estimations. The final section offers concluding observations.

\section{Basic empirical model}

In this paper, social trust formed by long-term interpersonal interaction is considered to play an important role on how firms invest ${ }^{4}$. I assume that the production function takes the form of the target input model and apply the model employed in the existing literature to this research (Wilson 1975; Jovanovic and Nyarko 1994; Rosenzweig 1995; Bardhan and Udry 1999; Yamauchi 2001). The main feature of the target input model is that an agent such as a firm manager determines the input after obtaining the relevant information, yielded by experience, about the optimal input. A risk neutral agent $j$ that is taken as a manager can produce goods at period $t$. Input and output levels are denoted as $z_{j t}$ and $q_{j t}$, respectively. The production function is defined as

$$
q_{j t}=1-\left(y_{j t}-z_{j t}\right)^{2},
$$

where

$$
y_{j t}=\theta_{j}+w_{j t}
$$

is a random target that fluctuates around parameter $\theta_{j}$ representing the ability of $j$. $w_{j t}$ is an i.i.d. normal variate with a mean of zero and variance of $\sigma^{2}{ }^{2}$. A firm manager knows $\sigma^{2}{ }_{w}$. Hence, he does not observe $\theta_{j}$ directly, but rather has some prior beliefs about it. $E(\cdot)_{t}$ and $\operatorname{var}_{\mathrm{t}}(\cdot)$ denote the conditional expectation and conditional variance at $t$, respectively. The optimal decision and the resulting expected output are

\footnotetext{
${ }_{4}$ Putnam (1993) asserts that social capital as presented in the case of Italy is considered to consist of local public goods. Following this argument, here social trust is taken as local public goods.
} 


$$
z_{j t}=E_{t}\left(y_{j t}\right)=E_{t}\left(\theta_{j}\right)
$$

$$
E_{t}\left(q_{j t}\right)=1-\operatorname{var}_{t}\left(\theta_{j}\right)-\sigma_{w}^{2}
$$

In each period $t$, a firm manager can obtain information and then decide the input level $z_{j t}$, which is equivalent to $E\left(\theta_{j}\right)$. Then, this process of decision making related to production is repeated. That is, a manager produces a good at $t$ and then at the end of period $t$ observes $y_{j t}$, thereby updating the prior variance concerning the optimal output level. Further, $\rho_{0}=1 / \operatorname{var}_{0}\left(\theta_{j}\right)$ is assumed to be the level of precision of a manager's expectation before starting production. $\rho_{1}=1 / \sigma^{2}{ }_{w}$. is the level of precision after obtaining the information through the previous experience of production. According to the Bayesian model, vart $\left(\theta_{j}\right)$ is represented as

$$
\operatorname{var}_{t}\left(\theta_{j}\right)=\frac{1}{\rho_{0}+N_{j t} \rho_{l}} .
$$

$N_{j t}$ denotes the number of productions manager $j$ has experienced at period $t$. $E_{t}(q)$ can thus be rewritten as

$$
E_{t}\left(q_{j t}\right)=1-\frac{1}{\rho_{0}+N_{j t} \rho_{l}}-\sigma_{w}^{2} .
$$

Here, let us assume that local capital plays a critical role in a limited area while global capital plays an important role in an unlimited area. For instance, the number of years of operation of a firm located in a suburban cluster has been taken as a proxy for local capital (social trust) ${ }^{5}$. A firm with a greater number of years of operation has survived for a longer period, indicating its superiority and sustainable good business relationships within its business partners of the same cluster, which further add to the firm's reputation ${ }^{6}$. As a consequence, community members are more likely to trust a firm of longer standing. On the other hand, the human capital accumulated by school education is thought to be unlimited to a particular area, and therefore it can be the proxy for global capital. Both of local and global capital affect productivity through the improvement of the precision of expectations ${ }^{7}$. Accordingly, $\rho_{0}=\rho_{o}(L, G), \rho_{l}=\rho_{l}(L, G)$, where L and G are the local and the global

\footnotetext{
${ }^{5}$ McMillan and Woodruff (1999) use duration of trading relationship as a proxy for the degree of reliability.

6 As discussed later, prior to the 1980s production was mostly conducted within the Kojima region, regarded as a garment cluster. Business partners were thus almost exclusively local community members.

7 The arguments of the existing literature are similar with this research in assuming that the precision of expectations depends upon school education (Rosenzweig 1995; Yamauchi 2001); they do not consider how social trust affects precision.
} 
capital, respectively. Furthermore, referring to the developing phase and the developed phase in the developmental process as Phase A and Phase B, respectively, I consider the effect of local and global capital upon learning. I also assume that the features of local capital and global capital for Phase A are the opposite in Phase B.

\section{Phase A}

In the developing phase, firms are thought to tend to produce goods in a limited area. Firms with larger local capital, hence, would be more able to access the available information when they start business. Accordingly, these firms can improve their precision of expectation. Further, having larger local capital enables firms to understand informal local rules more accurately and deeply ${ }^{8}$. These firms end up learning to follow the local rules since they can calculate the cost caused by suffering ostracism if they violate them. Consequently, firms initially deal with other local firms repeatedly, thereby strengthening their business connections within the local community. As a result, these firms are expected to gradually economize their transaction costs to improve performance. That is, the repeating of production and business transactions seems to improve the precision of expectation. Thus, the following assumption can be presented.

(Assumption 1) $\quad \frac{\partial \rho_{0}}{\partial L}>0, \frac{\partial \rho_{l}}{\partial L}>0$

Under a condition where an agent is constrained by local rules, global capital does not affect access to information. Hence, global capital makes only a minimal contribution to the improvement of the precision of expectation. In addition, global rules have an effect upon the extent to which an agent understands the generalized rules that are not limited to within a community, while not affecting the degree of understanding about local rules. Accordingly, an agent with greater global capital is expected to engage in more optimal behavior, which is not constrained by local rules. This might be why agents in such a condition have a greater tendency to engage in behaviors against the local rules, and as a result become more likely to suffer ostracism by the local community members. Once an agent has suffered ostracism and lost local trust, it is very difficult to rebuild cooperative relationships with business partners within the local community. Inevitably, the experiences of agents with global capital results in a deterioration of the precision of expectation. I thus provide the following assumption.

8 Kandori (1992) defines such a local rule as the social norm. 
(Assumption 2) $\quad \frac{\partial \rho_{0}}{\partial G} \approx 0, \frac{\partial \rho_{l}}{\partial G}<0$

In this case, theorem ( $1 A$ ) is postulated as below.

\section{Theorem (1A)}

(1) The larger the local capital, the larger the expected yield becomes.

(2) The larger the amount of production, the larger the expected yield becomes.

(3) If $\rho_{l}$ is sufficiently small, the larger the local capital and the more one experiences production, the larger the expected yield becomes ${ }^{9}$.

(Proof)

Differentiating the expected yield with respect to the local capital,

$$
\frac{\partial q_{j t}}{\partial L_{j t}}=\gamma\left[\frac{\partial \rho_{0} / \partial L_{j t}+N_{j t}\left(\partial \rho_{l} / \partial L_{j t}\right)}{\left(\rho_{0}+N_{j t} \rho_{l}\right)^{2}}\right]>0 .
$$

Differentiating the expected yield with respect to amount of production experience,

$$
\frac{\partial q_{j t}}{\partial N_{j t}}=\gamma\left[\frac{\rho_{l}}{\left(\rho_{0}+N_{j t} \rho_{l}\right)^{2}}\right]>0
$$

Further, differentiating equation (i) with respect to $N_{j t}$,

$$
\frac{\partial^{2} q_{j t}}{\partial L_{j t} \partial N_{j t}}=\gamma\left[\frac{-2\left(\partial \rho_{0} / \partial L_{j t}\right) \rho_{l}+\left(\partial \rho_{l} / \partial L_{j t}\right)\left(\rho_{0}-\rho_{l} N_{j t}\right)}{\left(\rho_{0}+N_{j t} \rho_{l}\right)^{3}}\right]>0 .
$$

From (i)(ii), (1) and (2) hold. From (iii), (3) holds. Q.E.D.

Under the same assumption, theorem (1B), concerning global capital, can be derived. The proof of this theorem is obtained by the same procedure as theorem (1A), differentiating (i) and (iii) with respect to $G$ instead of $L$.

\section{Theorem (1B)}

9 The condition that $\sigma^{2}$. be sufficiently small appears to be pertinent to developing countries that envisage similar drastic economic change. Hence, the assumption that $\rho_{t}=1 / \sigma_{w}^{2}$. is small enough seems convincing. On the other hand, Jovanovic and Nyarko (1996) focused on the degree of $\rho o$, which determines the choice of technology and thereby also economic growth. 
(1) The larger the global capital, the smaller the expected yield becomes.

(2) The larger the amount of production, the larger the expected yield becomes.

(3) If $\rho_{l}$ is sufficiently small, the larger the global capital and the more one experiences production, the smaller the expected yield becomes.

\section{Phase B}

As the cluster develops, the location of production tends to move toward the outside of the community. Hence, a firm is less constrained by local rules, and global capital begins to play a critical role in enhancing production. This is because local capital increases the effects of learning through production experience. On the other hand, a firm with larger local capital that is strongly trusted by its business partners within the community is more likely to continue to conduct business in the same manner, with the aim of maintaining its business relationships formed through long-term transactions. Due to this inertia, that is, path dependence, such a firm has presumably more difficulty in relocating its production base towards the outside of the cluster. Under this condition, a firm locally trusted among community members seems to have fewer learning effects from the experience of moving production outside of the community, because the local rules that has been thus far obeyed by the firm are not formerly or generally recognized, and as such not equivalent to the general rules. This may be why the effects of local capital and global capital on expected yield are thought to be opposed in Phase $\mathrm{A}^{10}$. Hence, assumptions 3 and 4 of Phase B are completely opposite those of Phase A:

$$
\begin{array}{ll}
\text { (Assumption3) } & \frac{\partial \rho_{0}}{\partial G}>0, \frac{\partial \rho_{l}}{\partial G}>0 \\
\text { (Assumption4) } & \frac{\partial \rho_{0}}{\partial L} \approx 0, \frac{\partial \rho_{l}}{\partial L}<0
\end{array}
$$

Then, the following theorems are obtained in the same way as the previously presented proof.

\section{Theorem (2A)}

(1) The larger the global capital, the larger the expected yield becomes.

10 Fafchamps argued that trust can be categorized into generalized trust and personalized trust and that generalized trust yields more efficient outcomes than personalized trust (Fafchamps 2006). Local capital (social trust) as defined in this paper is more equivalent to personalized trust rather than to generalized trust. 
(2) The larger the amount of production, the larger the expected yield becomes.

(3) If $\rho_{l}$ is sufficiently small and the global capital large, then the amount of production experience increases the expected yield.

\section{Theorem (2B)}

(1) The larger the local capital, the smaller the expected yield becomes.

(2) The larger the amount of production, the larger the expected yield becomes.

(3) If $\rho_{l}$ is sufficiently small and the local capital large, then the amount of production experience decreases the expected yield.

Summing up the discussion presented thus far in this section, in the developing stage where the market does not yet sufficiently function, the social trust among community members plays an important role. This stage corresponds to Phase A, in which social trust is considered to comprise local public goods (Hayami 2001). Within the community, which is not open to the outside world, there are social norms taken as rules locally formed. If a community member violates these norms, they will suffer from ostracism even if their actions are based on rational behavior without community-based constraints (Greif 1994; Kandori 1992; Hayami 2001). On the other hand, one can accumulate global and generalized knowledge through formal school education, which appears to be irrelevant to social norms. Therefore, school education might have a detrimental effect rather than a positive effect upon the updating of the precision of expectation.

When an economy develops and enters the stage where the market mechanism comes to function well, the importance of school education increases with respect to dealing with strangers. At this 'developed' stage, which corresponds to Phase B, economic activity extends from within a community toward the world outside. As a result of this change, one can do business more efficiently outside of the community even when suffering from ostracism inside the community. Accordingly, a firm manager is able to make optimal decisions without the constraints of local rules $^{11}$. Herein, although school education is predicted to improve the precision of expectation, the social trust within a community prevents a manager from coping with the change of economic circumstance swiftly, despite playing the important role at the local level. ${ }^{12}$ The following empirical hypotheses are therefore raised in

11 Greif (1994) uses commercial transactions among Mediterranean traders in the medieval age to suggest how institutions shifted from transaction relations based upon informal rules to those based on formal rules.

12 The reason why human capital has a positive effect upon production is because under circumstances in which an economy has matured and the market has come to expand 
order to examine the theorems and conjectures presented thus far.

\section{Hypothesis 1}

In the developing stage, the association of social trust and manager experience is complementary when managers operate production. Subsequently, in the developed stage, this association becomes substitute.

\section{Hypothesis 2}

In the developing stage, the association of school education and manager experience is substitute when managers operate production. Subsequently, in the developed stage, this association becomes complementary.

\section{Overview of the garment cluster in Kojima}

\subsection{Data sources and collection}

The firm level data used in this paper to perform the empirical analysis is composed of both officially published data and original survey data collected from each target firm. The officially published data source is the Manual of Enterprises in the Textile Industries: Volume for Western Japan [Zenkoku Sen-i Kigyou Yoran by Shin-yo Kokan Jo (1970-2006)]. This source provides data on total revenue (including revenue generated from production outside the Kojima cluster), a brief history of each enterprise, and a biographical sketch of the enterprise managers including their education history and birth place. The Manual, however, does not include the decomposed revenues generated from production in Kojima and other areas. The data reconnaissance was conducted in 2004 in order to better analyze the overall patterns of development and the transformation of the Kojima garment cluster. Subsequently, for the purpose of obtaining additional supplementary information covering an approximately 40-year period including the years 1968, 1978, 1988, 1998, and 2005, surveys of about 40

and diversify, the features of human capital are more smoothly adapted to the changes in economic conditions and have greater technological externality than the features of social trust. Considering only technological externality, however, cannot fully account for why social trust also has a detrimental effect. In order to explain the reason why social trust and human capital come to have opposite effects in the long term developmental process, the following factors should be analyzed: (1) Business relationships should be considered from the viewpoint of industrial organization; for instance, the transaction cost for subcontracting seems to affect economic performance. (2) The relative importance of capital changes when technology changes (Salvanes and Tveteras 2004). The social norm becomes "the vintage capital," and thus decreases efficiency due to changes in the economic circumstances. 
existing firms were carried out in 2005 and 2006.

Before turning to a description of the data, I briefly describe the sampling procedure employed in the 2005 and 2006 surveys. The survey was conducted in collaboration with the Association of the Garment Industry in Oakayama prefecture, which provided a member list of 107 registered firms. Although there were a large number of unregistered firms, I believe that the registered firms are representative of the firms in the Kojima cluster because the list covers the various types of firms, as described in detail later. Given my resource constraints, I was unable to conduct a census of the entire Kojima cluster, which would have allowed me to randomly sample firms from this list for the survey. The survey took a month to complete, and information was collected from 35 firms. In the process of collecting the questionnaires, I conducted informal interviews with about 40 enterprise managers. While the main limitation of the dataset is its relatively small sample size, it also has the advantage of making possible an assessment of the changing importance of social trust and human capital in the developmental process of the garment cluster.

\subsection{Brief history}

The setting for the empirical analysis is the town of Kojima, Japan. As shown in Figure 1, Kojima is located in Okayama prefecture, in western Japan, facing the Setonai Sea and surrounded by mountains, leading to a scarcity of arable land. In addition to these factors, the amount of rainfall is not high, resulting in low agricultural yields and a comparative advantage for non-agricultural sectors. The Kojima region used to be known as a textile-producing cluster during the 17 and 19 centuries, that is, during the $E d o$ and Meiji periods, and then it became known for producing tabi (Japanese traditional socks made of fabric) in the early $20^{\text {th }}$ century, i.e., during the Taisho period (Tawada 1957). Subsequently, using existing technology of tabi production, the Kojima region began producing clothes and then eventually emerged as the main cluster of school uniform production. Prior to World War II, the share of school uniform and work clothes production in Kojima reached $85 \%$ of all domestic production in Japan (Tawada 1957).

In the post-war period, especially during the 1950s, many firms entered the garment industry, with the number of garment firms surpassing 100 (San-yo Newspaper Publishing 1977). The production share of school uniforms and work clothes of the Kojima region continued to be the highest in Japan (Yamamura et al. 2003). The increase in the number of garment firms resulted in an upsurge of competition among them. In addition, the major textile firms supplying materials for 
school uniform production began restricting their business partners to large firms, leading to the drastic grouping of enterprises. Small scale firms thus became unable to purchase textiles, causing them to cease production of school uniforms. Subsequently they were pressured to exit the market (Kakuta 1971). Such drastic changes in the business environment caused firms to be excluded from the major business groups and seek 'niche markets' in which there seemed to be latent demand ${ }^{13}$. For example, some small firms attempted to enter the market for jeans and 'office lady' uniforms, markets that emerged mainly due to the socio-economic changes stemming from the inflow of western culture in the post-war period. The managers who decided to enter niche markets were considered 'entrepreneurs' and triggered economic development through innovation (Shumpeter 1912). As a consequence, the Kojima region came to be very famous for not only school uniforms and work clothes but also jeans and office lady uniforms.

According to the interview data, in the 1960s young and skilled labor resources were abundant in the Kojima region, not only from the local Kojima town but also from the surrounding rural areas of the Kyushu and Shikoku islands ${ }^{14}$. Such a seemingly 'unlimited' supply of cheap labor was no longer available in the 1970s. Hence, in order to continue to enjoy a cheap labor force, the garment firms of the Kojima region began to rely on subcontract firms outside of Kojima and the establishment of branch factories and subsidiaries mainly in the Kyushu and Shikoku islands. Subsequently, since the beginning of 1990, although the much lower wages and the considerable improvement of worker skills available through China producers have been an attractive option for many of the Kojima firms, the actual transfer of production bases to China has yet to commence due to the unique characteristics of the Kojima region clothes firms, which are discussed in the following sub-section ${ }^{15}$. In either case, the shift of production bases over a span of more than 30 years is shown in Figure 2, which depicts the changes in proportion of sales revenue generated by Kojima region firms, despite the sales likely being to other parts of Japan rather than abroad. Figure 2 reveals that the ratio of production taking place in the Kojima region was about $60 \%$ in 1968, but then declined

13 Kunio Ohshima, the founder of 'Betty Smith,' known as the first to specially produce ladies' jeans, expressed during an interview that the Tokyo Olympics held in 1964 were an epoch-making event that appeared to raise the demand for Western clothes such as jeans.

14 A similar pattern was also observed in the Bingo region, which was a major garment cluster second only to the Kojima region (Yamamura et al. 2003).

15 According to my interviews, although some firms that were mainly work clothes producers relocated their production bases to China, these cases were relatively uncommon within the Kojima region. 
steadily over time to less than $20 \%$ in 2005 . This indicates that whereas production was previously mainly based upon business relationships within the community, the importance of community based business networks decreased remarkably over time.

\subsection{Characteristics of clothes and production systems}

Although there have been various kinds of clothes produced in the Kojima region, its firms can be roughly categorized into two types in terms of the kinds of clothes they produce: school uniform producers and jeans producers. As mentioned previously, the former is regarded as a traditionally produced type of clothes while the latter is regarded as a new type of clothes introduced by innovative managers. Generally speaking, garment production is organized in a large number of stages. The fundamental stages are knitting, cutting, and stitching. Additional stages also become important depending upon the kinds of clothes and quality of product, because rises in income levels during the process of economic development cause consumers to demand more fashionable and refined clothes than before. Accordingly, the roles played by stages such as dyeing, calendaring and printing can become critical in determining how and the extent to which products are fashionable and meet consumer demand. This was especially true after the mid-1980s.

Although the school uniform, by definition, does not vary for one school, there is remarkable variation in uniforms among schools. According to my interview data, the educational market has become very competitive, leading schools to differentiate their school uniforms from others with the aim of recruiting more students. Indeed, these days there are even school uniforms designed by prominent designers, such as Hanae Mori. As for jeans, production it is characterized by the various special stages involved, such as washing, blustering, damaging and remaking, all of which require a certain degree of skilled labor that is generally centered in the cluster of production (Marshall, 1920). Firms are expected to enjoy agglomeration economies in response to changing demand for their products by using experienced, high skilled labor. However, contrary to this expectation, in actuality firms tended to shift their production base to areas outside of Kojima, as shown in Figure 2.

Here it is necessary to deal carefully with production systems. Figure 3, showing changes in proportion produced by internal production, indicates that the internal production ratio declined from slightly less than $90 \%$ in the 1960 s to about $60 \%$ in the 1980s and then was stable until 2005. From the data in Figures 2 and 3, I derived the argument that firms continued to mainly rely upon internal production rather than other means such as subcontracting, which would have involved shifting 
the production base outside of the Kojima region. This is presumably because the transaction costs between makers and subcontractors are more apt to increase due to the increasing difficulty in checking product quality in advance under conditions where the quality of products must improve while their diversity increases. Further, transaction costs are higher when the locations of subcontractors are distant from their subcontracting firms compared to when they are near. This implies that location and the internal structure of production seems to be determined jointly in order to minimize total costs.

The school uniform is characterized as a package order on a massive scale originating from newly registered students when the Japanese new school year begins every April. In the case of Japan, makers start production after receiving orders from those students who successfully passed the entrance examinations, which are ordinarily held in February. Then there is a need to deliver the products in time for the entrance ceremony in April. Thus, at most it can take no more than two months to complete such large-scale orders for incoming students. In reality, however, school uniform makers can to a certain extent calculate the expected quantity of orders in advance and therefore begin production of the normal sizes, even if there are subsequent variations in the orders from small to large sizes. However, there still remains the possibility of orders from 'outliers', i.e., those who require extremely large or small sizes. Hence firms must confront uncertainty and are thus required to flexibly and promptly deal with irregular orders. In sum, it is necessary for school uniform makers to achieve punctual delivery while at the same time dealing with irregular orders flexibly and promptly. Such conditions are also considered to raise transaction costs, and thus firms tend to take advantage of internal production resources with the aim of economizing transaction costs.

\subsection{Initial economic conditions and changes in the roles of social trust and human capital.}

Now let us consider how the situation of the Kojima garment cluster is relevant to Hypotheses 1 and 2, which are derived from the simple theoretical model described in Section 2. As mentioned previously, the Kojima region has the unique geographical features of being surrounded by mountains and the sea. Further, prior to the advent of modern transportation, such as railways or automobiles, the inflow of strangers from outside the Kojima region was limited; the Kojima community was considered to be a closed society. Local norms were likely formed independent of the outside world due to 
scarce contact with the outside. In this research, the local norm is defined as the local rule in the closed community. That is to say, local rules are limited within a community but not followed in the outside world ${ }^{16}$. Local rules are based on conventions, which is judged from the inside of the community, not the outside (Sugden 1989). Compared to these local rules, rules that are not limited to a particular area are called global rules.

According to field research conducted in the Bingo region, which is also a major garment cluster in Japan, a trading company employee doing business with a Bingo partner said 'It is impossible to do business unless one enters the Bingo region and becomes well acquainted with its culture and history' (Yamamura 2005). My field research for the current study indicates that the Kojima region is similar to the Bingo area on this point. This presumably is why one must have much knowledge about the business conventions of a particular region in order to enter smoothly into business relationships. These business conventions, which cannot exist in the market in the sense of neoclassical economics, formed gradually though long-term and intensive personal interactions. These local rules and norms based on conventions obviously differ from rules of transaction generally recognized by trading company employees. As such, knowledge about local rules and norms cannot be obtained through school education. For instance, there is the case of a manager born in the Bingo community who graduated from a prestigious university in Tokyo but failed in business after returning to the Bingo region in the 1960s and 1970s (Yamamura 2005). Yamamura (2005) indicated through his interview that this manager's failure might have been due to the fact that he was unable to sufficiently understand the local rules in the long run despite his great business knowledge and ability. I also observed a similar case in the Kojima region through my field research. Taken together, the above facts suggest that local rules exist in the Kojima region.

Though local rules seemingly have a detrimental effect upon a firm's performance, they also are considered to make a contribution to the firm from a different viewpoint. The Ozaki Shoji corporation is well-known as a very successful and long-standing firm, established in 1929. It seems to be plausibly argued that it takes long time for a firm to establish social trust as a brand and a good reputation through repetitive transactions. Ozaki Shoji seems to have been able to form social trust within the Kojima region through long term business relations with the subcontractors and wholesalers of the Kojima region. Fusajiro Ozaki, who was the manager of Ozaki Shoji

16 Local rules provide various types of contracts, such as the commercial contracts and contracts between makers and subcontractors. 
as well as chairman of the Association of the Garment Industry of Japan, was honored by not only employees of Ozaki Shoji but also individuals involved in the garment industry and residents of the Kojima community ${ }^{17}$. This is because he worked not only for Ozaki Shoji but also for the good of the local community. He often took part in various meetings and become a man of influence in the Kojima region. On the other hand, Fusajiro Ozaki also played a substantial role in the steadily growing the Ozaki Shoji business for more than 30 years from the beginning of the 1950s to the mid-1980s. It follows from this that one of the main reasons for the growth and dominance of Ozaki Shoji is because Fusajiro Ozaki was well acquainted with the local rules, and he took advantage of the social trust Ozaki Shoji generated since being established in Kojima.

Following the discussion above, it seems that it was very difficult for outsiders whose home town was not Kojima to do business smoothly in its relatively closed area. But just how different are the ways of doing business between the home town, or native, managers born in Kojima and the outsiders? Because I am particularly interested in comparing the locations of the production bases and production systems of firms managed by native managers with those managed by outsiders, the sample is divided according to the hometown of the managers, as shown in Table $1^{18}$. The numbers in parentheses, indicating the actual number of observations, indicates that the number of native managers is distinctly larger than that of outsider managers.

Since the sample size is relatively small, I have decided to combine my survey data for 1968 and 1978, which are regarded as the developing stage years, and that for 1988, 1998 and 2006, which are regarded as the developed stage. I begin with the rates of production in the Kojima region in the left part of Table 1. The rates of production in Kojima in the developing stage were higher than that in the developed stage for both the native Kojima managers and the outsider managers. This rate of native mangers is higher than that of the outsider managers in the developing stage, but it becomes roughly the same in the developed stage. As has been demonstrated in studies of the garment cluster in India, native managers seem to have much stronger social ties within a cluster compared to outsider managers (Banerjee and Munshi 2004). The fact that the Kojima native managers have social connections with those with whom they work might have made it easier for them to do business with a large number of subcontractors inside the Kojima region during the developing stage. This might be why the Kojima native managers tended to produce their products within the Kojima

17 Toshiaki Motoyama, the executive director of the Association of the Garment Industry in Okayama Prefecture, told me the story about Fusajiro Ozaki.

18 According to my interviews, some managers were born outside of the Kojima region and thus are defined as outsiders in Kojima. 
region using subcontractors, a conclusion consistent with the fact that the rate of internal production of the Kojima native managers was lower than that of the outsider managers in the developing stage, as shown in the right part of Table 1.

Subsequently, when Kojima firms were confronted with the abovementioned business environment changes in the developed stage, the Kojima native managers were forced to shift their production bases to outside of the region, leading to the production rates of their firms in Kojima to be comparable to those of the outsider managers. In the developed stage, when the quality upgrade of products took place, calling for a larger number of product stages and more skilled labor, it seems to have become very difficult to manage subcontractors due to the lack of social ties in the remote locations of the subcontractors and the lack of experienced labor, resulting in cost increases. Therefore, internal products seem to have become relatively more important in raising firm performance than before. From the right part of Table 1, it can be seen that the internal product rate of the native managers became higher than that of the outsider managers in the developed stage, despite being lower in the former stage. This implies that native managers are more likely to produce higher quality products than outsider managers in response to the rising demand for a larger variety of fashionable and high quality clothes.

In the early stages of cluster development, most production is conducted within the cluster. As the cluster enters later stages of development, production bases tend to shift to outside areas. As shown in Figure 2, this process is observed in the case of the Kojima garment cluster. My conjecture is as follows: local rules had a significant effect within the Kojima cluster, such that firms with greater local capital such as social trust were able to carry out higher levels of output in the early stage of development. In the subsequent stage, however, firms were not as constrained by local rules and hence global capital, such as human capital, rather than social trust came to make a greater contribution to the level of output.

\section{Empirical estimation}

In this section I estimate the determinants of firm size from 1968 to 2005 in terms of sales revenue in order to test the Hypotheses presented thus far ${ }^{19}$. Then, 2SLS estimation, in which I use the instrumental variables to obtain the predicted values of endogenous independent variables, is employed to control for the problem of

19 This paper follows the same line of reasoning as existing literature (Hall and Jones 1997; Banerjee and Munshi 2004), where the level of output is considered to represent economic performance. 
endogeneity.

\subsection{Empirical strategy}

Following the assumption of Yamamura et al. (2003) that the size of a firm is a reasonable indicator of firm performance, I specified the following regression equation 20 :

$$
\begin{aligned}
& \operatorname{Ln}(F S I Z E)_{i t}=\alpha_{0}+\alpha_{1} \operatorname{Ln}(T R U S T)_{i t}+\alpha_{2} \operatorname{Ln}(H C)_{i t}+\alpha_{3} \operatorname{Ln}(E X P E)_{i t} \\
& \quad+\alpha_{4} \operatorname{Ln}(T R U S T)_{i t}{ }^{*} \operatorname{Ln}(E X P E)_{i t}+\alpha_{5} \operatorname{Ln}(H C)_{i t}{ }^{*} \operatorname{Ln}(E X P E)_{i t}+\alpha_{6} \operatorname{Ln}(T R U S T)_{i t} * \operatorname{Ln}(H C)_{i t} \\
& \quad+\alpha_{7} \operatorname{Ln}(T R U S T)_{i t}{ }^{*} \operatorname{Ln}(E X P E)_{i t}{ }^{*} Y 6878+\alpha_{8} \operatorname{Ln}(H C)_{i t} t^{*} \operatorname{Ln}(E X P E)_{i t}{ }^{*} Y 6878 \\
& \quad+\alpha_{9} \operatorname{Ln}(T R U S T)_{i t}{ }^{*} \operatorname{Ln}(H C)_{i t}{ }^{*} Y 6878+\alpha_{10} C L U S T E R_{i t}+\alpha_{11} I N T E R_{i t}+\varepsilon_{i}+\omega_{i t},
\end{aligned}
$$

where TRUSTrepresents the rate of trust in prefecture $i$ in year $t$, and $\alpha$ s represents the regression parameters. $\varepsilon_{i}$ represents the unobservable firm-specific effects of $i \mathrm{~s}$ firm (a fixed effect firm vector ) ${ }^{21}$. $\omega_{i t}$ represents the error term. Fixed effects estimation is employed in order to control for unobserved individual effects using panel data (Baltagi 1995). Labor, capital, and input, which are taken as production factors, can not be captured due to data limitations, and thus the risk of estimation bias is big. In order to attenuate this bias, the unobserved firm fixed effects are controlled for.

Log of Firm Size, denoted as $\operatorname{Ln}($ FSIZE $)$, is the dependent variable determined by various factors captured by the independent variables, as described below 22 . Following the discussion in Section 2, the years of operation of a firm since its establishment, TRUST, is incorporated as a proxy for social trust (local capital). A manager's years of schooling, $H C$, is considered to represent human capital (global capital). Years of experience as manager, EXPE, is thought to represent the learning effect of being a manager ${ }^{23}$. FSIZE, TRUST, HC, and EXPE take log form and hence the coefficients of TRUST, HC, and EXPE can be taken as the elasticity. Moreover, the their respective cross terms, $\operatorname{Ln}(T R U S T)_{i t}{ }^{*} \operatorname{Ln}(E X P E)_{i t}, \operatorname{Ln}(H C)_{i t^{*}} \operatorname{Ln}(E X P E)_{i t}$, are

20 Firm performance could not be estimated using the production function since the input and capital data could not be obtained.

21 Banerjee and Munshi (2004) pointed out the problem of firm experience being subject to a cohort effect, suggesting that it is controlled for by firm fixed effects.

22 Firm size is measured by the sales revenue deflated by the price index of garment products, which is available from the Bank of Japan (1970-2006).

23 Years of manager experience were measured by the years that had passed since the present manager become manager. Most of these present managers did not coincide with the founding managers since the present managers were often the sons of former mangers. This means that manager experience is different from the total years of operation of firms. 
included to assess the influences of social trust (local capital) and human capital (global capital) on the learning effect ${ }^{24}$. In addition, these interaction effects are thought to change over time during the long-term development process of the Kojima region garment cluster. In response to these changes, the signs and absolute value of each coefficient are thus expected to change. To capture these changes in interaction terms, I added the interaction terms as additional interactions with the developing stage dummy, represented as Y6878, which takes a value of 1 if the year value is 1968 or 1978, otherwise it takes a value of 0 . They are represented as Ln(TRUST) $)_{i t}{ }^{*}$ $\operatorname{Ln}(E X P E)_{i t} * Y 6878$ and $\operatorname{Ln}(H C)_{i t} * \operatorname{Ln}(E X P E)_{i t,}{ }^{*} Y 6878$.

From Hypotheses 1 and 2, and working from the simple theoretical model presented in Section 2, I derive the following predicted signs of each interaction term: social trust (local capital) is predicted to improve the learning effects through experience in the developing stage, whereas it is will hamper the learning effects in the developing stage due the changes in the economic environment. Accordingly, compared with the developed stage, social trust convincingly makes a contribution to firm performance in the developing stage. The coefficient of $\operatorname{Ln}(T R U S T)_{i t}{ }^{*} \operatorname{Ln}(E X P E)_{i t}$ ${ }^{*}$ Y6878 is thus expected to take a positive sign. In contrast, human capital (global capital) is predicted to impede learning effects through experience in the developing stage, whereas it will raise the learning effects in the developed stage. Therefore, compared with the developing stage, human capital makes a contribution to firm performance in the developed stage. As predicted theoretically, the sign of $\operatorname{Ln}(H C)_{i t}$ * $\operatorname{Ln}(E X P E)_{i t} *$ Y6878 turns out to be negative.

With respect to the expected signs derived from the field research, in the developing stage, improvement of firm performance is regarded as the outcome of the production rates within the Kojima region, denoted as CLUSTER it, due to the agglomeration economies stemming from the abundance of skilled labor, division of labor and especially the economization of transaction cost. The subcontract network within a tightly knitted community is regarded as relatively more effective in improving firm performance than internal production, which is represented as $I N T E R_{i t}{ }^{25}$. After entering the developed stage, however, internal production becomes more important than the subcontract network in maintaining high performance because of the

24 Yamauchi (2004) also incorporated the schooling interacted with the experience to examine whether schooling and experience is complementary when wage equation is estimated. Banerjee and Munshi (2004) use the interaction term of experience and the manager home town dummy as an independent variable.

${ }_{25}$ As is presented in Table 2, both CLUSTER and INTER varied from 0 to 100 and therefore it is impossible to take log form. 
relocation of production bases to the outside of the Kojima region as well as the changing demand for product variety and high quality fashionable clothes. Taken together, these lead to the predictions that CLUSTER ${ }_{i t}^{*} Y 6878$ and INTER ${ }_{i t}^{*} Y 6878$ take positive and negative signs, respectively.

\subsection{Estimation results}

Before examining the statistical results, it is useful to first look at the basic statistics shown in Table 2. The wide variations in most variables, such as FSIZE, TRUST, EXPE, CLUSTER and INTER indicate that the features of the firms used as the sample are rich in diversity; this indirectly implies that the sampling is nearly random.

To begin with, the results of the regression analysis are presented in Table 3. The results of a Hausman test, which is concerned with the null-hypothesis that there is a systematic difference between the fixed and random effects estimators, is presented in the second row from the bottom. 'Yes' suggests that there is no systematic difference between the models. This means that the random effects model can be justified in all cases and therefore is employed instead of the fixed effects model. The results of the cross terms of $\operatorname{Ln}(T R U S T)_{i t} * \operatorname{Ln}(E X P E)_{i t}$ and $\operatorname{Ln}(H C)_{i t}{ }^{*} \operatorname{Ln}(E X P E)_{i t}$ presented in all columns take negative and positive signs, respectively, while being statistically significant. This means that social trust hampers the learning effect, whereas human capital ameliorates it. The coefficients of $\operatorname{Ln}(T R U S T)_{i t}{ }^{*} \operatorname{Ln}(E X P E)_{i t}$ in absolute values ranging between 0.35 and 0.46 are smaller than those of $\operatorname{Ln}(H C)_{i t}{ }^{*} \operatorname{Ln}(E X P E)_{i t}$, which range from 0.58 to 0.69 . The positive influence of $\operatorname{Ln}(\mathrm{HC})_{i t}$ on learning turned out to outweigh the negative influence of social trust, which shows, to a larger extent, the importance of human capital in improving firm performance through learning effects. With respect to the cross terms with the developing stage dummy, Ln(TRUST) $)_{i t}$ * $\operatorname{Ln}(E X P E)_{i t} * Y 6878$ and $\operatorname{Ln}(H C)_{i t} * \operatorname{Ln}(E X P E)_{i t} * Y 6878$, in columns (2), (5) and (6) take significant positive and negative signs, respectively. I interpret this result as follows: The studied period ranging from 1968 to 2005 seems to belong to the developed stage as a whole from a historical point of view. More precisely, however, the period from 1968-1978 appears to belong to the end of the developing stage, in which social trust (local capital) played a relatively important role in the improvement of firm performance. This may have been because, as shown in Figure 2, the rates of production within the Kojima region in the period from 1968-1978 are distinctly higher than those of the period from 1988-2005. Thus, the results of estimations concerning social trust (local capital) and human capital (global capital) are consistent with 
Hypotheses 1 and 2.

As for CLUSTER and INTER in Table 3, all the signs of CLUSTER are positive, while all the signs of INTER are negative; further, all were statistically significant. This implies that a firm with a higher rate of production within the Kojima region is more likely to be small. On the other hand, a high rate of internal production leads is associated with a large firm. I derive from these observations the argument that a firm that produces its products in a lower wage area than Kojima and uses internal production to economize transaction costs tends to ameliorate its performance. Accordingly, agglomeration economies that stemmed from the use of subcontractors disappeared due to the drastic change in economic circumstances. As presented in columns (4) and (6), these variables interacted with the developing stage dummy, that is, CLUSTER ${ }^{*}$ Y6878 and INTER ${ }^{*} Y 6878$, taking positive and negative signs, respectively, with the signs of $C L U S T E R^{*} Y 6878$ being statistically significant but those of INTER $*$ Y6878 being insignificant. It follows that firms relatively benefited from the agglomeration economies and flexible production of subcontract networks in the developing stage, a conclusion that appears to be congruent with my expected results derived from the historical overview of the Kojima region.

The choice of location of production and production internalization seems also to be taken as an outcome of firm performance. If this is the case, the causality among them becomes ambiguous, resulting in estimation bias. Here it is necessary to deal carefully with this bias. To this end, the findings are subjected to random effect estimation for more careful scrutiny using the instrumental variable strategy. The estimation results of the EC2SLS random effects model, which allows me to control for endogeneity bias, are shown in Table 4 (Baltagi 1995). The instruments of INTER and CLUSTER, regarded as endogenous variables, are the outsider manager dummy, which takes 1 if a manager's home town is not Kojima and otherwise 0, and the non-log values of TRUST, HC, and EXPE. A manager's home town is determined exogenously in the distant past and has a significant effect upon the location of production and rates of internal production, as discussed in the previous section. This is why the outsider dummy is an adequate instrument. Table 4 shows that the same pattern obtained in Table 3 continues to be obtained.

The signs of $\operatorname{Ln}(\text { TRUST) })_{i t} * \operatorname{Ln}(E X P E)_{i t}$ and $\operatorname{Ln}(H C)_{i t} * \operatorname{Ln}(E X P E)_{i t}$ are unchanged and their coefficients become larger and more significant, with the exception of column(4), when the alternative estimation is employed. Further, the firm size continues to become more elastic with respect to $\operatorname{Ln}(H C)_{i t}{ }^{*} \operatorname{Ln}(E X P E)_{i t}$ than to $\operatorname{Ln}(T R U S T)_{i t} * \operatorname{Ln}(E X P E)_{i t}$. In addition, the cross terms of these variables and the 
developing stage dummy, $\operatorname{Ln}(\text { TRUST })_{i t} * \operatorname{Ln}(E X P E)_{i t}{ }^{*} Y 6878$ and $\operatorname{Ln}(H C)_{i t}{ }^{*} \operatorname{Ln}(E X P E)_{i t}$ *Y6878 also continue to take positive and negative signs, despite being statistically insignificant in column (3). These results in Table 4 are consistent with those of Table 3. The signs of CLUSTER and INTER are the same as those presented in Table 3. However, the fact that the results of CLUSTER are not statistically significant with the exception of column(4) is different from Table 4, meaning that production within the Kojima region did not hamper firm performance. It can plausibly be asserted that skilled labor and prompt responses are substantially important for Kojima firms due to the consumer-driven features of clothes. This might be why production located in the Kojima region does not have a detrimental effect upon firm performance. As for CLUSTER ${ }^{*}$ Y6878 and INTER ${ }^{*} Y 6878$, these coefficient signs do not change despite being statistically insignificant.

Up to this point we have presented various estimated results. In sum, we arrive at the conclusion that taken together, the estimation results examined in this section are both consistent with and support reasonably well Hypotheses 1 and 2, put forward in the preceding section. Moreover, I found that these results are in line with the dynamics of location choice and production systems over time.

\section{Conclusion}

It is often pointed out, and indeed widely acknowledged, that both social trust, comprised of local capital formed through long-term intensive human relationships, and human capital, comprised of the global capital accumulated by school education, are considered to cause economic development. However, validity of the former is limited to within a tightly knit group such as a community, whereas the role played by the latter is generally effective. On the other hand, learning based on experience, which tends to update one's expectations and thereby improve the precision of decision making, seems to also make a contribution to economic development. The relative importance of these factors appears to change in response to the transition of economic circumstances. Nevertheless, such a dynamic process has yet to be fully explored. In addition, little is known about how the associations among them evolve and change over time in the long term. This research uses panel data of the Japanese garment cluster at the firm level to investigate how the influences of social trust and human capital on learning effects changed over time in response to drastic environmental changes in the garment industry, in which production bases were shifted from the central cluster to the outside.

The results of regression estimations, after controlling for unobserved firm-specific 
effects, were as follows:

(1) In the developing stage, the manager of a firm makes decisions and learns from their outcomes under conditions constrained by local rules, which are regarded as the social norms. In such a situation, social trust was found to improve the learning effect. That is, social trust and learning is complementary.

(2) In the developed stage, in which an ideal market emerges, a manager's decision making is not constrained by local rules. Due to environment changes, human capital accumulated through school education improves the learning effect, while social trust comes to have a detrimental effect on leaning. Put differently, the association of social trust and learning becomes substitute, and that of human capital and learning becomes complementary.

The argument can be derived from what I have suggested thus far that economic development entails institutional change partly due to the geographical extension of place in which business and production are conducted. Such institutional changes cause the effects of social trust and human capital on learning to become altered.

The present research was limited to a particular area, and the range of ages and sample size of the subjects used in the analyses was very small. As such, the findings provided so far can not be generalized to a large degree. In order to better verify the generality of the arguments presented here, additional research, such as a comparable study using a larger sample size, should be conducted. 


\section{References}

Alesina, A., La Ferrara, E. 2002. Who trust others? Journal of Public Economics 85. 207-234.

Baltagi, B.H. (1995). Econometric Analysis of Panel Data. Chichester: John Wiley \& Sons.

Banarjee, A.V and E. Duflo. (2000). "Reputation Effects and the Limits of Contracting: A Study of the Indian Software Industry," Quarterly Journal of Economics, Vol. 115, No.3, pp. 989-1017.

Banarjee, A.V and K. Munshi. (2004). "How Efficiently is Capital Allocated? Evidence from Knitted Garment Industry in Tirupur," Review of Economic Studies, Vol. 71, pp. 19-42.

Bank of Japan (1970-2006) Bukka Shisu Nenpo (Annual Report of Price Indexes). Bank of Japan, Statistical Bureau.

Bardhan, P and C. Udry. (1999). Development Microeconomics. Oxford: Oxford University Press. Chapter12, Part II .

Coleman, J.S., 1990. Foundation of Social Theory, Harvard University Press, Cambridge, MA.

Fafchamps, M., 2006. Development and Social Capital. Journal of Development Studies 42, $1180-98$

Foster, A and M. Rosenzweig. (1995). "Learning by Doing and Learning form Others: Human Capital and Technical Change in Agriculture," Journal of Political Economy, Vol.103, No.6, pp. 1176-1209.

Fukuyama, F., 1995. Trust: Social Virtues and the Creation of Prosperity. The Free Press.

Goux,D., Maurin, E., 2007. Close neighbors matter: neighborhood effect on early performance at school. Economic Journal 117, 1193-1215.

Granovetter, M., 1985. Economic action and social structure: the problem of embeddedness. American Journal of Sociology 23, 481-510.

Greif, A. (1994). "Cultural Belief and the Organization of Society: A Historical and Theoretical Reflection on Collectivist and Individualist Societies," Journal of Political Economy, Vol102, No.5 , pp. 912-950.

Hall, R.E., Jones, C.I., 1999. Why do some countries produce so much more output per worker than others? Quarterly Journal of Economics 114. 83-116.

Hayami, Y. (2001). Development Economics: From the Poverty to the Wealth of Nations. Oxford University Press, New York.

Jovanovic, B and K. Nyarko. (1996). "Learning by Doing and the Choice of Technology," 
Econometrica, Vol. 64, No.6, pp. 1299-1310.

Kakuta.N, 1971. A tale of Kojima is number one. (Kojima Nippon-ichi Monogatri), Kojima Lions Club.

Kandori, M. (1992). "Social Norms and Community Enforcement," Review of Economic Studies, Vol. 59, No.1, pp.63-80.

Knack, S., 2003.Groups, growth and trust: Cross-country evidence one the Olson and Putnam hypothesis. Public Choice 117, 341-355.

Knack, S., Keefer, P., 1997. Does social capital have an economic payoff? A cross-country investigation. Quarterly Journal of Economics 114, 83-116.

Maddala, G. (1983). Limited-Dependent and Qualitative Variables in Econometrics, Cambridge: Cambridge University Press.

Marshall, A. (1920). Principles of Economics: An Introductory Volume. New York. Macmillan.

McMillan, J. and C. Woodruff. (1999). "Interfirm Relationship and Informal Credit in Vietnam," Quarterly Journal of Economics, Vol. 114, No.4, pp. 1285-1320.

Miguel, E., Gertler, P., and Levine, D., 2005. Does social capital promote industrialization? Evidence from a Rapid Industrializer. Review of Economics and Statistics 87, 754-762.

Munshi, K., 2003. Social learning in a heterogeneous population: technology diffusion in the Indian Green Revolution. Journal of Development Economics 73, 185-213.

Putnam, R D., 1993. Making Democracy Work: Civil Traditions in Modern Italy. Princeton: Princeton University Press.

Putnam.R. D, 2000. Bowling alone: The collapse and revival of American community, A Touchsotne book, New York.

Rosenzweig, M.R. (1995). "Why Are There Returns to Schooling?," American Economic Review , Vol. 85, No. 2, pp. 153-158.

Salvanes, K..G., Tveteras, R. (2004). "Plant Exit, Vintage Capital and the Business Cycle," Journal of Industrial Economics, Vol. 52 , pp. 255-276.

San-yo Newspaper Publishing., 1977. The Industrial climate of Seto-uchi. (Seto-uchi Fudo-ki), San-yo Newspaper Publishing.

Schultz, T.W. (1975). "The Value of the Ability to Deal with Disequilibria," Journal of Economic Literature, Vol. 13, No. 3, pp. 827-846.

Schumpeter, J., 1912. The Theory of Economic Development: An Inquiry into Profits, Capital, Credit, and Business Cycle. Oxford University Press, New York.

Sugden, R. (1989). “Spontaneous Order," Journal of Economic Perspective, Vol. 3, No.89, pp. 85-97. 
Tawada, K., 1959. The History of Kojima, Vol.1. (Kojima no Rekishi Dai 1 kan), Kojima Rekishi Kanko-kai.

Vega-Redondo, F. (2006). Building up Social Capital in a Changing World. Journal of Economic Dynamics and Control 30, 2305-2338.

Wilson, R. (1975). "Informational Economies of Scale,” Bell Journal of Economics,Vol.6, No.1:, pp. 184-195.

Yamagishi, T., Cook, K., and Watabe, M., 1998. Uncertainty, trust, and commitment formation in the United States and Japan. American Journal of Sociology 104, 165-194.

Yamamura, E., Sonobe, T., Otsuka, K., 2003. Human capital, cluster formation, and international relocation: The case study of the garment industry in Japan, 1968-98. Journal of Economic Geography 3, 37-56.

Yamamura, E., 2005. Social Capital, Human Capital, and the Dynamics of Learning: The Case of the Development and the Transformation Garment Industry in Bingo Region. (In Japanese) ,Economic Review (Keizai Kenkyu) 56, 111-22.

Yamauchi, F. (2004), "Are Experience and Schooling Complementary? : Evidence from Migrants' Wage Dynamics in the Bangkok Labor Market," Journal of Development Economics, Vol.74, pp.489-513.

Zak, P., Knack, S., 2001. Trust and Growth. Economic Journal 111, 295-321. 

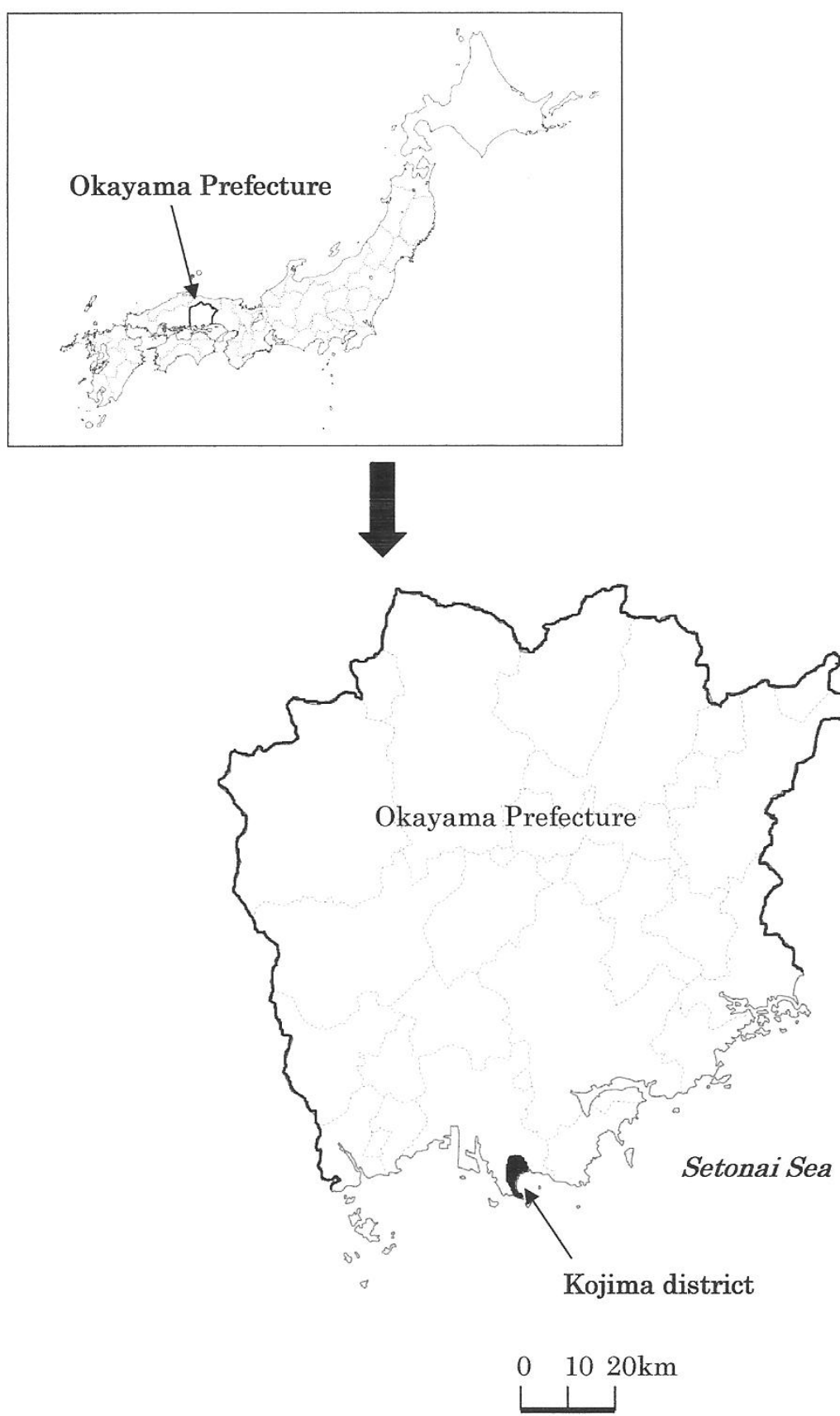

Figure 1. Location of the Kojima garment cluster in Okayama prefecture 


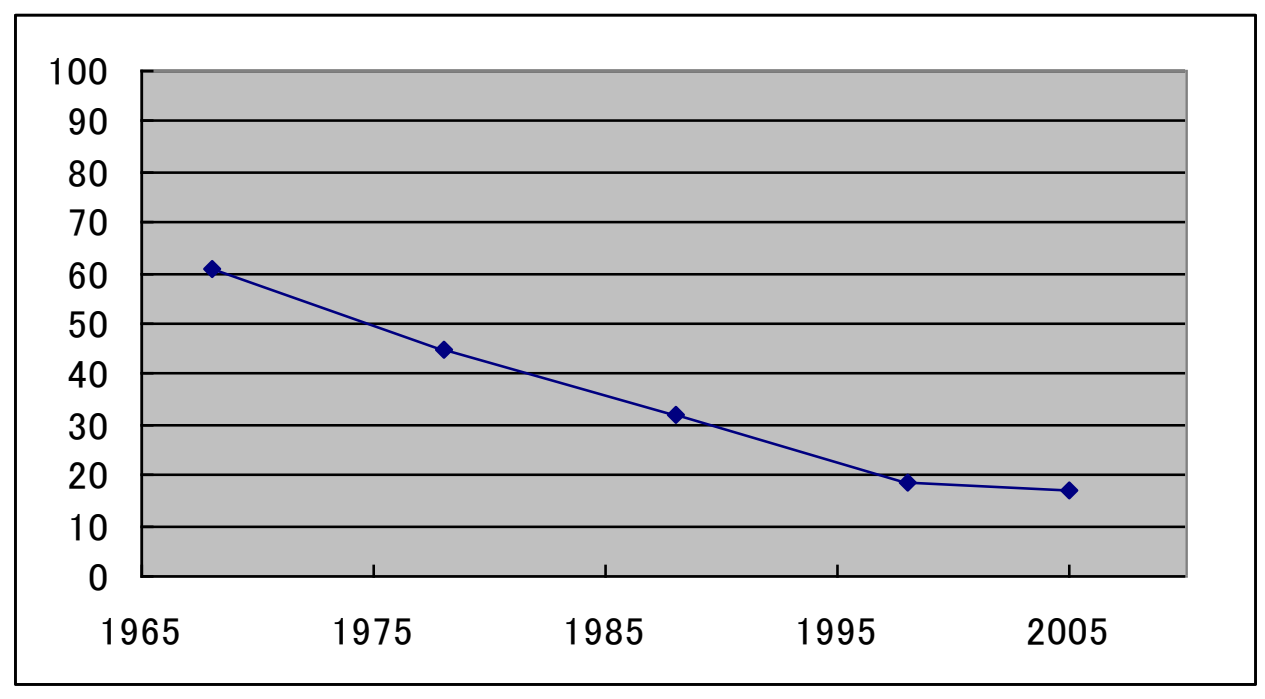

Figure 2. Proportion of sales revenue generated by Kojima area (\%) 


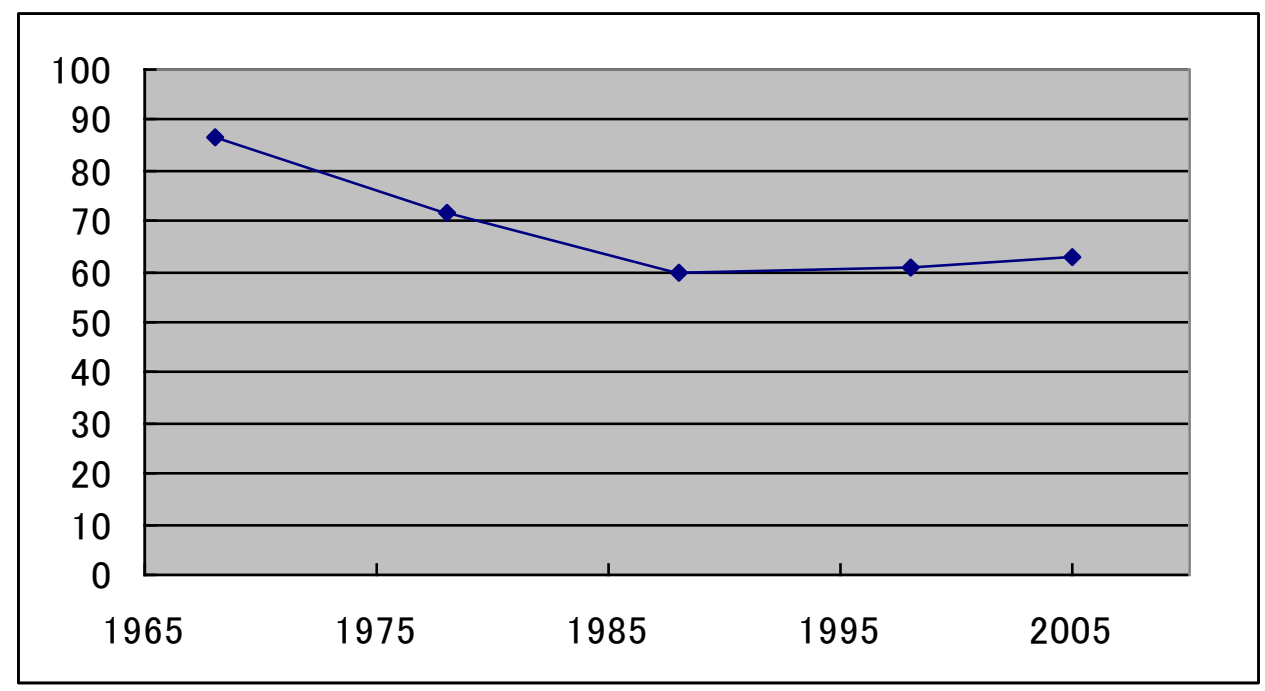

Figure 3. Proportion of sales revenue by internal production (\%) 
Table 1 Rates of Kojima production and internal production (\%)

\begin{tabular}{|c|c|c|c|c|}
\hline & \multicolumn{2}{|c|}{ Kojima } & \multicolumn{2}{|c|}{ Internal } \\
\hline & Native & Outsider & Native & Outsider \\
\hline \multirow[t]{2}{*}{$1968-78$} & 59.7 & 49.7 & 58.6 & 64.7 \\
\hline & (46) & (20) & (46) & (20) \\
\hline \multirow[t]{2}{*}{$1988-2005$} & 34.3 & 35.2 & 49.8 & 37.9 \\
\hline & (84) & (20) & (84) & (20) \\
\hline
\end{tabular}

Notes: Numbers in parentheses are observations. 
Table 2 Descriptive statistics

\begin{tabular}{|c|c|c|c|c|c|}
\hline Variables & Definition & Mean & $\operatorname{Max}$ & Min & $\begin{array}{l}\text { Standard } \\
\text { deviation }\end{array}$ \\
\hline FSIZE & Sales revenue a) & 245 & 3,110 & 6 & 438 \\
\hline TRUST & Years of operation & 43 & 94 & 3 & 19 \\
\hline$H C$ & Manager's years of education & 13 & 16 & 6 & 3 \\
\hline$E X P E$ & Manager's years of experience & 17 & 55 & 1 & 12 \\
\hline CLUSTER & $\begin{array}{l}\text { Proportion of sales revenue by } \\
\text { Kojima district }\end{array}$ & 43 & 100 & 0 & 33 \\
\hline INTER & $\begin{array}{l}\text { Proportion of sales revenue by } \\
\text { internal production }\end{array}$ & 52 & 100 & 0 & 32 \\
\hline
\end{tabular}

Notes: a) millions of yen. 
Table 3

Determinants of sales revenue (Random Effects Model)

\begin{tabular}{|c|c|c|c|c|c|c|}
\hline & (1) & (2) & (3) & (4) & (5) & (6) \\
\hline $\operatorname{Ln}(T R U S T)$ & $\begin{array}{l}4.22^{* *} \\
(2.36)\end{array}$ & $\begin{array}{l}4.18^{* *} \\
(2.35)\end{array}$ & $\begin{array}{l}3.56^{*} \\
(2.03)\end{array}$ & $\begin{array}{l}3.70^{*} \\
(2.09)\end{array}$ & $\begin{array}{l}3.40^{*} \\
(1.91)\end{array}$ & $\begin{array}{l}3.80^{*} \\
(2.20)\end{array}$ \\
\hline $\operatorname{Ln}(H C)$ & $\begin{array}{l}2.28 \\
(1.01)\end{array}$ & $\begin{array}{l}2.70 \\
(1.18)\end{array}$ & $\begin{array}{l}1.13 \\
(0.51)\end{array}$ & $\begin{array}{l}1.22 \\
(0.55)\end{array}$ & $\begin{array}{l}1.26 \\
(0.56)\end{array}$ & $\begin{array}{l}1.93 \\
(0.86)\end{array}$ \\
\hline $\operatorname{Ln}(E X P E)$ & $\begin{array}{l}-0.20 \\
(-0.23)\end{array}$ & $\begin{array}{l}0.06 \\
(0.06)\end{array}$ & $\begin{array}{l}-0.26 \\
(-0.30)\end{array}$ & $\begin{array}{l}-0.19 \\
(-0.22)\end{array}$ & $\begin{array}{l}0.002 \\
(0.00)\end{array}$ & $\begin{array}{l}-0.02 \\
(-0.03)\end{array}$ \\
\hline $\begin{array}{c}\operatorname{Ln}(T R U S T)^{*} \\
\operatorname{Ln}(E X P E)\end{array}$ & $\begin{array}{l}-0.35^{*} \\
(-2.01)\end{array}$ & $\begin{array}{l}-0.46^{*} \\
(-2.36)\end{array}$ & $\begin{array}{l}-0.36^{*} \\
(-2.18)\end{array}$ & $\begin{array}{l}-0.38^{*} \\
(-2.22)\end{array}$ & $\begin{array}{l}-0.46^{* *} \\
(-2.39)\end{array}$ & $\begin{array}{l}-0.46^{* *} \\
(-2.43)\end{array}$ \\
\hline $\begin{array}{l}\operatorname{Ln}(H C)^{*} \\
\operatorname{Ln}(E X P E)\end{array}$ & $\begin{array}{l}0.58^{*} \\
(1.83)\end{array}$ & $\begin{array}{l}0.66^{*} \\
(2.07)\end{array}$ & $\begin{array}{l}0.63^{*} \\
(2.05)\end{array}$ & $\begin{array}{l}0.62^{*} \\
(2.01)\end{array}$ & $\begin{array}{l}0.68^{*} \\
(2.16)\end{array}$ & $\begin{array}{l}0.69^{*} \\
(2.25)\end{array}$ \\
\hline $\operatorname{Ln}(T R U S T) *$ & $-1.18^{*}$ & $-1.19^{*}$ & -0.91 & -0.94 & -0.87 & $-1.05^{*}$ \\
\hline $\operatorname{Ln}(H C)$ & $(-1.92)$ & $(-1.94)$ & $(-1.54)$ & $(-1.56)$ & $(-1.42)$ & $(-1.74)$ \\
\hline $\begin{array}{l}\operatorname{Ln}(T R U S T) * \\
\operatorname{Ln}(E X P E) * Y 6878\end{array}$ & & $\begin{array}{l}0.24^{* *} \\
(2.33)\end{array}$ & & & $\begin{array}{l}0.18^{*} \\
(1.74)\end{array}$ & $\begin{array}{l}0.22^{*} \\
(2.15)\end{array}$ \\
\hline $\operatorname{Ln}(H C) *$ & & $-0.36^{* *}$ & & & $-0.28^{*}$ & $-0.32^{*}$ \\
\hline $\operatorname{Ln}(E X P E) * Y 6878$ & & $(-2.34)$ & & & $(-1.82)$ & $(-2.12)$ \\
\hline $\operatorname{Ln}(T R U S T)^{*}$ & & 0.005 & & & 0.01 & -0.01 \\
\hline $\operatorname{Ln}(H C) * Y 6878$ & & $(0.12)$ & & & $(0.27)$ & $(-0.33)$ \\
\hline CLUSTER & & & $\begin{array}{l}-0.008^{* *} \\
(3.17)\end{array}$ & $\begin{array}{l}-0.01^{* *} \\
(3.60)\end{array}$ & $\begin{array}{l}-0.008^{* *} \\
(3.12)\end{array}$ & $\begin{array}{l}-0.01^{* *} \\
(3.52)\end{array}$ \\
\hline INTER & & & $\begin{array}{l}0.006^{* *} \\
(279)\end{array}$ & $0.007^{* *}$ & $\begin{array}{l}0.006^{* *} \\
(2.38)\end{array}$ & $0.006^{*}$ \\
\hline CLUSTER *Y6878 & & & & $\begin{array}{l}0.006^{*} \\
(1.90)\end{array}$ & & $\begin{array}{l}0.008^{*} \\
(2.11)\end{array}$ \\
\hline INTER *Y6878 & & & & $\begin{array}{l}-0.004 \\
(-1.50)\end{array}$ & & $\begin{array}{l}-0.004 \\
(-0.94)\end{array}$ \\
\hline $\begin{array}{c}\text { Hausman } \\
\text { test }\end{array}$ & Yes & Yes & Yes & Yes & Yes & Yes \\
\hline $\begin{array}{l}\text { Breusch-Pagan } \\
\text { test }\end{array}$ & 0.00 & 0.11 & 0.00 & 0.20 & 0.00 & 0.13 \\
\hline Sample & 140 & 140 & 140 & 140 & 140 & 140 \\
\hline
\end{tabular}

Notes: Numbers in parentheses are z-statistics. * and ** indicate significance at 5 and 1 percent levels, respectively (one-sided tests). In each of the estimates, year dummies are included but not reported to save space. 
Table 4

Determinants of sales revenue (EC 2SLS Random Effects Model)

\begin{tabular}{|c|c|c|c|c|}
\hline & (1) & (2) & (3) & (4) \\
\hline Ln(TRUST) & $\begin{array}{l}5.16^{*} \\
(2.31)\end{array}$ & $\begin{array}{l}4.96 * * \\
(2.47)\end{array}$ & $\begin{array}{l}4.69 * \\
(2.24)\end{array}$ & $\begin{array}{l}4.62^{*} \\
(2.26)\end{array}$ \\
\hline $\operatorname{Ln}(H C)$ & $\begin{array}{l}2.51 \\
(0.89)\end{array}$ & $\begin{array}{l}2.67 \\
(1.07)\end{array}$ & $\begin{array}{l}2.60 \\
(0.96)\end{array}$ & $\begin{array}{l}3.71 \\
(1.38)\end{array}$ \\
\hline $\operatorname{Ln}(E X P E)$ & $\begin{array}{l}-0.03 \\
(-0.04)\end{array}$ & $\begin{array}{l}0.02 \\
(0.03)\end{array}$ & $\begin{array}{l}0.11 \\
(0.11)\end{array}$ & $\begin{array}{l}-0.004 \\
(-0.00)\end{array}$ \\
\hline $\begin{array}{c}\operatorname{Ln}(T R U S T) * \\
\operatorname{Ln}(E X P E)\end{array}$ & $\begin{array}{l}-0.47 * * \\
(-2.57)\end{array}$ & $\begin{array}{l}-0.45^{* *} \\
(-2.55)\end{array}$ & $\begin{array}{l}-0.52^{* *} \\
(-2.55)\end{array}$ & $\begin{array}{l}-0.43^{*} \\
(-2.14)\end{array}$ \\
\hline $\begin{array}{l}\operatorname{Ln}(H C) * \\
\operatorname{Ln}(E X P E)\end{array}$ & $\begin{array}{l}0.70^{*} \\
(2.20)\end{array}$ & $\begin{array}{l}0.65^{*} \\
(2.13)\end{array}$ & $\begin{array}{l}0.71^{*} \\
(2.25)\end{array}$ & $\begin{array}{l}0.64^{*} \\
(1.99)\end{array}$ \\
\hline $\begin{array}{l}\operatorname{Ln}(T R U S T) * \\
\operatorname{Ln}(H C)\end{array}$ & $\begin{array}{l}-1.36^{*} \\
(-1.82)\end{array}$ & $\begin{array}{l}-1.36^{*} \\
(-2.02)\end{array}$ & $\begin{array}{l}-1.29 * \\
(-1.78)\end{array}$ & $\begin{array}{l}-1.46^{*} \\
(-2.06)\end{array}$ \\
\hline $\operatorname{Ln}(T R U S T) *$ & & & 0.16 & $0.27 * *$ \\
\hline $\operatorname{Ln}(E X P E) * Y 6878$ & & & $(1.50)$ & $(2.32)$ \\
\hline $\operatorname{Ln}(H C) *$ & & & -0.26 & $-0.41 * *$ \\
\hline $\operatorname{Ln}(E X P E) * Y 6878$ & & & $(-1.60)$ & $(-2.42)$ \\
\hline $\begin{array}{l}\operatorname{Ln}(T R U S T) * \\
\operatorname{Ln}(H C) * Y 6878\end{array}$ & & & $\begin{array}{l}-0.003 \\
(-0.09)\end{array}$ & $\begin{array}{l}-0.17^{*} \\
(-1.90)\end{array}$ \\
\hline CLUSTER & $\begin{array}{l}-0.007 \\
(-0.83)\end{array}$ & $\begin{array}{l}-0.009 \\
(-1.28)\end{array}$ & $\begin{array}{l}-0.004 \\
(-0.66)\end{array}$ & $\begin{array}{l}-0.01 * * \\
(2.49)\end{array}$ \\
\hline INTER & $\begin{array}{l}0.01 * * \\
(2.54)\end{array}$ & $\begin{array}{l}0.01^{*} \\
(1.66)\end{array}$ & $\begin{array}{l}0.01 * \\
(2.01)\end{array}$ & $\begin{array}{l}0.009 \\
(0.14)\end{array}$ \\
\hline CLUSTER *Y6878 & & $\begin{array}{l}0.002 \\
(0.31)\end{array}$ & & $\begin{array}{l}0.01^{*} \\
(1.89)\end{array}$ \\
\hline$I N T E R * Y 6878$ & & $\begin{array}{l}-0.002 \\
(-0.32)\end{array}$ & & $\begin{array}{l}0.01 \\
(1.28)\end{array}$ \\
\hline Sample & 140 & 140 & 140 & 140 \\
\hline
\end{tabular}

Notes: Numbers in parentheses are $\mathrm{z}^{\text {-statistics. }{ }^{*} \text { and }}{ }^{* *}$ indicate significance at 5 and 1 percent levels, respectively (one-sided tests). Stranger dummy and non-log value of TRUST, $H C$ and EXPE are used as instruments in (1) and (3). Stranger dummy and the non-log values of TRUST, HC and EXPE and their cross terms with Y6878 are used as instruments in (2) and (4). 